\title{
Effects of Ultrasound, Laser and Exercises on Temporomandibular Joint Pain and Trismus Following Head and Neck Cancer
}

\author{
Hany Mohamed Elgohary, $\mathrm{PhD}^{1}$, Hadaya Mosaad Eladl, $\mathrm{PhD}^{1}$, \\ Ashraf Hassan Soliman, $\mathbf{P h D}^{1,2}$, Elsadat Saad Soliman, $\mathbf{P h D}^{3}$
}

\begin{abstract}
${ }^{1}$ Department of Physical Therapy for Surgery, Faculty of Physical Therapy, Cairo University, Giza;
${ }^{2}$ Faculty of Physical Therapy, Badr University in Cairo, Cairo; ${ }^{3}$ Department of Physical Therapy for Musculoskeletal Disorders and Its Surgery, Faculty of Physical Therapy, Cairo University, Giza, Egypt
\end{abstract}

Objective To compare the effects of low intensity ultrasound (LIUS), traditional exercise therapy (TET), low level laser therapy (LLLT) and TET on temporomandibular joint (TMJ) pain and trismus following recovery from head and neck cancer (HNC).

Methods Sixty participants following, who had experienced HNC, were randomly allocated to three groups of 20 people each. Each group received different therapy. Group A received LIUS and TET; group B received LLLT and TET; while group $C$ received TET. All 60 participants were evaluated under the visual analog scale (VAS), the University of Washington Quality of Life questionnaire (UW-QOL) and the Vernier caliper scale (VCS) at the beginning of the therapies and after 4 weeks.

Results ANOVA test revealed significant improvements across all three groups with outcomes of $p<0.05$. The results of the UW-QOL questionnaire showed a significant difference between groups A, B and C in favor of group $A(p<0.05)$. The VAS results showed a more improvement in group $A$ as compared to group $B(p<0.05)$, while there was no statistical difference between groups B and C ( $>0.05)$. The VCS results showed more improvement for the individuals in group $B$ as compared to those in group $C(p<0.05)$, while there was minimal difference between groups A and B ( $\mathrm{p}>0.05)$.

Conclusion The LIUS and TET are more effective than LLLT and/or TET in reducing TMJ pain and trismus following HNC.

Keywords Ultrasonics, Lasers, Trismus, Temporomandibular joint, Head and neck neoplasms

Department of Physical Therapy for Surgery, Faculty of Physical Therapy, Cairo University, El-Tahrir St. Dokki, Giza, Egypt. Tel: +20-2-3761-7691, Fax: +20-2-3761-7692, E-mail: gohary75pt@hotmail.com

ORCID: Hany Mohamed Elgohary (http://orcid.org/0000-0001-5531-1875); Hadaya Mosaad Eladl (http://orcid.org/0000-0002-4083-7070); Ashraf Hassan Soliman (http://orcid.org/0000-0003-4223-1483); Elsadat Saad Soliman (http://orcid.org/0000-0002-1202-3416).

(c) This is an open-access article distributed under the terms of the Creative Commons Attribution Non-Commercial License (http://creativecommons.org/ licenses/by-nc/4.0) which permits unrestricted noncommercial use, distribution, and reproduction in any medium, provided the original work is properly cited. Copyright $\odot 2018$ by Korean Academy of Rehabilitation Medicine 


\section{INTRODUCTION}

The global yearly rate of head and neck malignancies is at a staggering more than 550,000 victims with nearly 300,000 becoming deceased [1]. These statistics make head and neck cancer (HNC) the sixth global common cancer by rate $[2,3]$. Trismus can be triggered by various reasons including but not limited to dental epidemics, tonsils abscesses, injuries of temporomandibular joint (TMJ) muscles, infectious diseases of the mandible, maxillofacial congenital deformities, or treatment radiotherapy for HNC $[4,5]$. Trismus was identified to develop at a rate of 5\%-38\% [6] after head and neck surgeries. Cancerrelated trismus occurs either as a result of the tumor itself or due to its treatment [7]. Tumor cells insinuate the muscles adjoining the TMJ, causing a reactive contraction of the muscles that act to close the mouth. Furthermore, the formation of scar and fibrous tissue, which correlates with using radiotherapy for the treatment of such tumors, constrained the movements of the mouth $[8,9]$. Multiple approaches have been recommended for the management of trismus including therapeutic exercises, electrotherapeutic modalities, computer-based equipment, and in some cases surgical interventions $[10,11]$. Other modalities such as stretching exercises that incorporate moist heat, low intensity ultrasound (LIUS) and transcutaneous electrical nerve stimulation (TENS) are preferred due to their ease of application and efficiency $[12,13]$.

LIUS is a modality used for the treatment of many skeletal muscle dysfunctions. Its mechanical energy, is transferred in the manner of acoustic compression waves to evoke thermal and mechanical physiological changes in the targeted tissue. This particular feature makes LIUS a common modality used for treatment. It was assumed that the mechanical strains of ultrasound provoke biochemical changes which accelerate the tissue repair [14]. The thermal physiological changes of LIUS include the increment of local tissue temperature, plenty of blood flow and improvement of the flexibility and extensibility of tissue with diminished fluid viscosity [15] making LIUS applicable in the management of trismus condition and for diminishing TMJ pain following HNC.

Neuromuscular stabilization is an example of a manual therapy technique used for the treatment of TMJ dysfunction [16]. The mastication muscles is used to implement a compressive power to the condylar disk through promot- ing the condylar-disk-eminence integrity and eventually recovering the muscle function. These procedures can additionally be employed as proprioceptive training to develop functional movements and concurrently diminishing pain [17].

Low level laser therapy (LLLT) reduces the inflammatory conditions without adverse consequences by lessening pain and swelling and supporting the repair of the tissue [18]. The force of LLLT in treating pain originating from soft-tissue trauma can be attributed to the indirect reduction of edema, bleeding, neutrophil activity, provocative cytokines and enzymatic action. LLLT reduces swelling and subsequent pain resulting in, enhanced tissue repair since lymphatic vessels regeneration is accelerated and the vascular permeability is minimized [19].

In fact, in the past few years, surgical, medical and conservative approaches have arose to treat trismus and TMJ pain with no predictable results [20]. In order to enhance the speed of recovery of these debilitation problems and to concrete the evidence of both LIUS and LLLT in managing such conditions, the study was monitored and evaluated. The aim of the present study is to compare the effects of LIUS plus traditional exercise therapy (TET), LLLT plus TET, and TET on TMJ pain and trismus following HNC.

\section{MATERIALS AND METHODS}

\section{Subjects}

Initially, 70 participants (33 females and 37 males) with trismus and pain following HNC were recruited from the National Cancer Institute in Cairo at the period from April 2016 to February 2017 with 60 of them (27 Females, 33 males) completing the study. The study was performed in accordance with the Declaration of Helsinki and approved by the Local Institutional Review Board of the Faculty of Physical Therapy at Cairo University (No. P.T.REC/012/001868). To detect a difference of $20 \%$ in the pain intensity gained by the treatment modalities between groups using visual analog scale (VAS), the study sample size was estimated with a power of $80 \%$ and a confidence level alpha $(=0.05)$. Therefore, while the sample size was assumed to be 20 participants per study group, the number was increased to 70 patients for the three groups taking into account the drop out throughout the study time. An informed written consent was signed 
by every participant while purpose, benefits, and potentials of the current clinical trial interventions were agreed upon with the participants.

Participants underwent physical assessment and their history noted. They were recruited in the study only if their clinical assessments revealed that they suffered from trismus and pain following HNC. Patients who had any medical conditions or health problems that may affect the results of the study as implants, pregnancy, sensitivity to phototherapy, or any neurological condition impacting the facial nerve as Bell's palsy were excluded from the study.

Participants were randomly allocated into three groups of 20 patients. Group A was subjected to LIUS plus TET program that included stretching exercises, passive and active range of motion exercises and strengthening exercises. Group B received LLLT plus TET, whereas group C received only TET. The principal investigator used concealed envelope randomization and the participants were then offered the allocated treatment. Both participants and investigators were blinded during the randomization and allocation processes.

\section{Measurement procedures}

Measurement of maximum mouth opening by using VCS

The amount of mouth mandibular opening (MMO) was estimated using the calculation of vertical distance between the incisal ends of upper and lower front teeth. Any incongruity of the mandible throughout opening and closing was also detected. A modified Vernier Caliper recorded the MMO, with the patients supporting their heads alongside a firm wall/surface in an erect position. After confirming the caliper gauge had no missing or worn out numbers and no scratches of the marking lines, patients were instructed to open their mouth as wide as they could, while the investigator estimated the maximum vertical distance between the incisal edges of the maxillary central incisor and the mandibular central incisor at the midline [21]. Three readings were recorded per patient and the average determined.

\section{UW-QOL questionnaire}

Based on our research, there is no standard questionnaire that should be used for the measurement of quality of life [22]. The one frequently used by clinicians in the United Kingdom is (UW-QOL), notably due to its simplic- ity and accuracy [23]. The fourth version of the UW-QOL questionnaire comprises of 12 sole question fields; pain, appearance, activity, recreation, swallowing, chewing, speech, shoulder, taste, saliva, mood, and anxiety. These fields require between 3 and 6 answer options all of which are scored consistently from 0 (worst) to 100 (best) according to the grading of response [24].

\section{Measurement of pain intensity using VAS}

VAS is a continuous horizontal line of length $(10 \mathrm{~cm})$ starting with no pain at the left side and gradually increasing pain towards the end of the line at the right side. A translated Arabic version of VAS was used [25].

Baseline measurements were taken at the beginning of the study and outcome measurements were carried out on 4 weeks later for each patient. To avoid inter examiner variability, all measurements were performed by a single examiner

\section{Treatment procedures}

\section{LIUS procedure}

LIUS therapy was conducted by a therapeutic ultrasound machine (Sonicator 740; Mettler Electronics Corp., Anaheim, CA, USA; output of AC=230 V @ $50 / 60 \mathrm{~Hz}$, max power consumption $=73 \mathrm{~W}$, and frequency $=1 \mathrm{MHz}$ ). Patients were encouraged to sit in a comfortable position while the LIUS therapy was applied at frequency of $1 \mathrm{MHz}$, pulsed mode $60 \%$ and a dose of $1.0 \mathrm{~W} / \mathrm{cm}^{2}$ for 5 minutes. unilaterally over the affected masseter muscle orally, 5 times a week for 4 consecutive weeks.

\section{LLLT procedure}

LLLT was conducted by use of laser equipment (Electro Medical Supplies (Greenham) Ltd., Wantage, Oxfordshire, UK). After preparation of the patient, goggles were provided to both patient and therapist as protective wear for the eyes, the infrared laser of wavelength $(950 \mathrm{~nm})$, output power $15 \mathrm{~mW}$, pulsed $80 \%$, at a dose of $4.3 \mathrm{~J} / \mathrm{cm}^{2}$, max energy density $\left(7.6 \mathrm{~J} / \mathrm{cm}^{2}\right)$ for 6 minutes. extra orally over the lateral aspect of the lower jaw unilaterally exactly over the affected masseter muscle, 5 times a week for 4 consecutive weeks.

\section{TET program}

The traditional exercise therapy was given to the three groups of the study as a form of passive and active range 
of motion, stretching exercises, and resistive mouth exercises. Each type of exercise was performed for a duration of 6 seconds and repeated 10 times. The exercises were performed twice a day, 5 times a week for 4 consecutive weeks $[26,27]$.

The sequence of the treatment for patients in group A involved the LIUS followed by 5 -minute rest period and then TET while the second dose of TET was done as a home care session. For patients in group B, the LLLT was administered, followed by 5 -minute rest period and then TET and the second dose of TET as a home care session as well. Group C received only TET as a home care program while visiting the outpatient clinic once a week. All patients were given extensive explanation on measurements and treatment procedures prior to engaging in the treatment program.

\section{Statistical analysis}

The averages and standard deviations for age, weight, height, and body mass index (BMI) were used as basic references for correlating data to estimate the central tendency. A paired t-test was used to obtain the differences within each group between baseline and post- treatment results, and Pearson chi-squared test was used to test the categorical variable of either female or male). Oneway analysis of variance (ANOVA) and post-hoc test were used to assess intergroup differences in various measurements. The results were considered statistically signifi- cant if the p-value less than 0.05. SPSS version 20 (IBM, Armonk, NY, USA) was used to analyze the data.

\section{RESULTS}

Seventy HNC survivors were invited to join this study based on the eligibility criteria of experiencing trismus and pain following HNC. Ten of them did not complete the study and were excluded because of various causes. Two did not meet the inclusion criteria and one declined to participate. Based on this, the final incorporated participants were 67 where they were allocated randomly into three groups. Group A and C both begun with 22 participants, while group B had 23 participants. Throughout the interventions, 7 participants dropped out; 2 of them joined another hospital and declined the treatment interventions, one experienced unprecedented medical problems, and another stopped the intervention because of unavailability of transportation. Three other participants changed their residential zones posing a challenge to their commitment. The final tally of participants reduced to 60 as is shown in Fig. 1.

It was proven that no significant differences in the bio demographic data of the three groups regarding age, weight, height, sex variable, and BMI ( $>0.05$ ) existed, indicating the uniformity and homogeneity of the participants as shown in Table 1.

The statistical analysis did not present any notable dif-

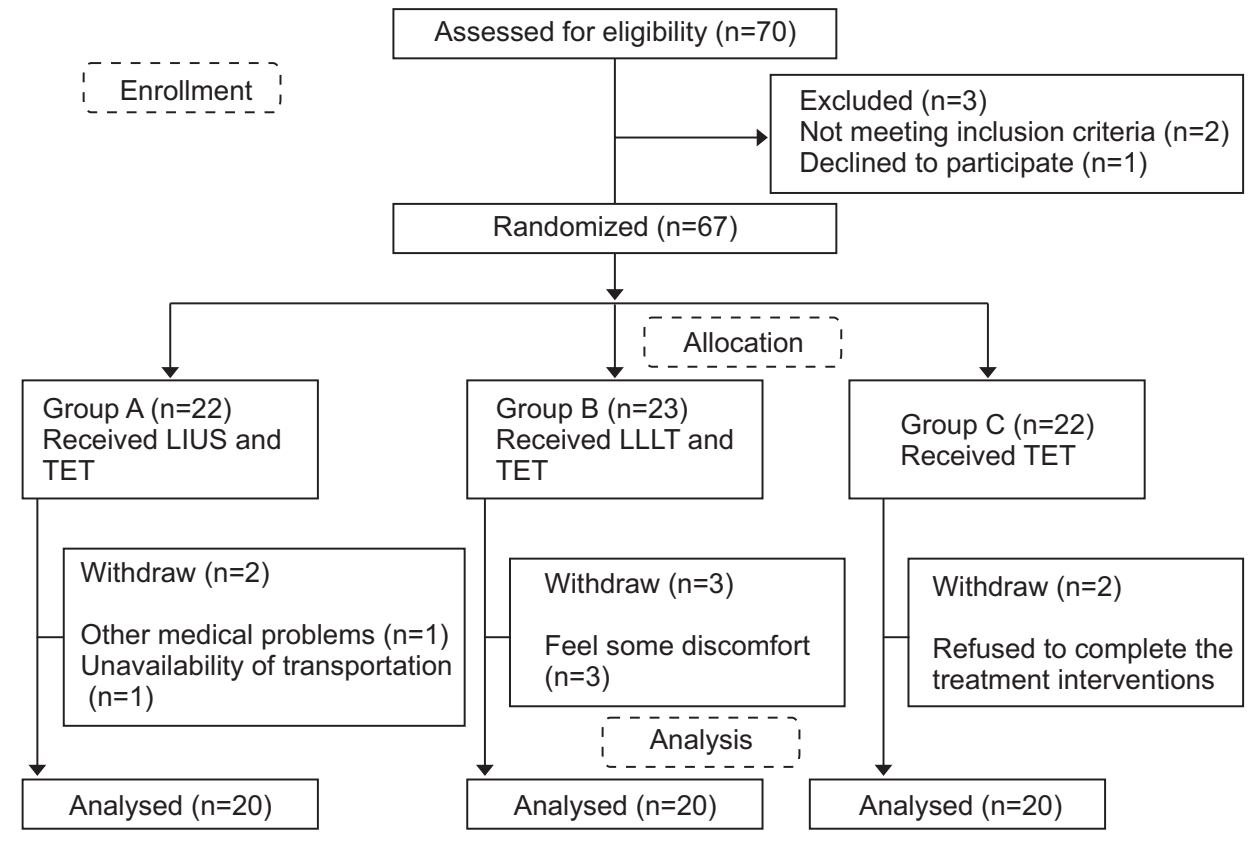

Fig. 1. Flowchart diagram of the study. LIUS, low intensity ultrasound; TET, traditional exercise therapy; LLLT, low level laser therapy. 
Table 1. Demographics of participants

\begin{tabular}{lcccc}
\hline \multicolumn{1}{c}{ Variable } & Group A & Group B & Group C & p-value \\
\hline Age $(\mathrm{yr})$ & $61.00 \pm 6.16$ & $60.75 \pm 5.09$ & $62.85 \pm 5.77$ & 0.450 \\
\hline Height $(\mathrm{m})$ & $1.69 \pm 0.010$ & $1.68 \pm 0.011$ & $1.69 \pm 0.010$ & 0.915 \\
\hline Sex & & & & 0.817 \\
Male & 11 & 10 & 12 & \\
\hline Female & 9 & 10 & 8 & 0.392 \\
\hline Weight $(\mathrm{kg})$ & $74.20 \pm 5.81$ & $76.55 \pm 5.75$ & $76.35 \pm 6.33$ & 0.288 \\
\hline BMI $\left(\mathrm{kg} / \mathrm{m}^{2}\right)$ & $25.99 \pm 1.95$ & $27.10 \pm 2.90$ & $26.88 \pm 2.03$ & \\
\hline
\end{tabular}

Values are presented as mean \pm standard deviation.

BMI, body mass index.

Table 2. Comparisons of UW-QOL, VAS, and VCS pre- and post-treatment for all groups

\begin{tabular}{ccccc}
\hline Variable & Group & Pre & Post & p-value \\
\hline UW-QOL & A & $40.65 \pm 8.32$ & $80.80 \pm 8.81$ & $<0.001^{*}$ \\
& B & $41.70 \pm 10.59$ & $73.30 \pm 4.95$ & $<0.001^{*}$ \\
& C & $39.15 \pm 9.29$ & $50.00 \pm 7.97$ & $<0.001^{*}$ \\
VAS $(\mathrm{cm})$ & $\mathrm{p}=0.694$ & $\mathrm{p}<0.001^{*}$ & $<0.001^{*}$ \\
& $\mathrm{~A}$ & $7.75 \pm 1.41$ & $2.65 \pm 1.50$ & $<0.001^{*}$ \\
& $\mathrm{~B}$ & $7.55 \pm 1.61$ & $3.85 \pm 1.66$ & $<0.001^{*}$ \\
VCS $(\mathrm{mm})$ & $\mathrm{C}$ & $7.70 \pm 1.08$ & $4.80 \pm 1.54$ & $<0.001^{*}$ \\
& $\mathrm{p}=0.893$ & $\mathrm{p}<0.001^{*}$ & $<0.001^{*}$ \\
& $\mathrm{~A}$ & $25.50 \pm 6.77068$ & $48.60 \pm 11.57$ & $<0.001^{*}$ \\
\hline
\end{tabular}

Values are presented as mean \pm standard deviation.

UW-QOL, University of Washington-Quality of Life; VAS, visual analog scale; VCS, Vernier caliper scale. ${ }^{*} \mathrm{p}<0.05$.

Table 3. Mean differences between the three groups post-treatment

\begin{tabular}{ccccc}
\hline Variable & Group A vs. Group B & Group A vs. Group C & Group B vs. Group C & p-value \\
\hline UW-QOL & $7.50^{*}$ & $30.80^{*}$ & $23.30^{*}$ & $<0.001^{*}$ \\
VAS $(\mathrm{cm})$ & $-1.20^{*}$ & $-2.15^{*}$ & -0.95 & $<0.001^{*}$ \\
VCS $(\mathrm{mm})$ & 4.20 & $14.15^{*}$ & $9.95^{*}$ & $<0.001^{*}$ \\
\hline
\end{tabular}

UW-QOL, University of Washington-Quality of Life; VAS, visual analog scale; VCS, Vernier caliper scale. ${ }^{*} \mathrm{p}<0.05$.

ferences at the beginning of the study for UW-QOL questionnaire, VAS and VCS among all groups $(p>0.05)$ as shown in Table 2.

At the end of the treatment, the three groups showed noteworthy statistical differences using ANOVA test and the post-hoc test in favor of group A $(\mathrm{p}<0.05)$ for UWQOL questionnaire as shown in Table 3.
For VAS, a remarkable difference was detected in favor of group A compared to group B and group C, while there were very minimal differences between groups $\mathrm{B}$ and $\mathrm{C}$. Moreover, the results of VCS revealed major differences in group $B$ compared to group $C(p<0.05)$, and negligible differences between groups A and B as shown in Table 3. 


\section{DISCUSSION}

In this study, a comparative analysis was performed to examine the effects of LIUS along with TET, LLLT along with TET, and TET on TMJ trismus and pain following HNC. At the end of the treatment, it was established that all the three treatment approaches were beneficial in managing TMJ dysfunctions based on the results of the UW-QOL questionnaire, VAS, and VCS. However, the highest improvement in all outcomes was observed in the group underwent LIUS along with TET.

In a study conducted by Lee et al. [28], it was concluded that trismus has a deteriorating effect on mouth function and the quality of life and consequently mouth exercises should be prescribed to improve the mouth function. There exists an alarming rate of trismus in subjects with HNC. Trismus critically diminishes the health-related quality of life and negatively affects daily living activities of subjects with HNC [29].

The current study showed remarkable improvement of patients' trismus and pain after the various therapy modalities. These results are parallel to a study conducted by Carrillo et al. [30] who reported that LLLT had a more impressive positive effect on trismus after third molar operation as compared to its placebo application which used He-Ne laser with a wavelength of $633 \mathrm{~nm}$, a power of $0.3 \mathrm{~W} / \mathrm{cm}^{2}$, and a dose of $10 \mathrm{~J} / \mathrm{cm}^{2}$ at different six points around the operation site with a spot of $1.5 \mathrm{~mm}$.

A different study conducted parallel to this one by Zecha et al. [31] observed that LLLT has a great effect in managing the side effects following chemoradiation therapy of HNC including trismus, dysgeusia, dysphagia, lymphedema, and speech problems.

Contrary to the above study, studies conducted by Roynesdal et al. [32] and Fernando et al. [33] reported that LLLT has no effect in the treatment of pain, swelling and trismus in TMJ dysfunction.

LIUS is considered as one of the electrophysiological modalities that ceases inflammation, enhances muscular relaxation and speeds up the blood flow to the target muscle and tendons. These physiological effects are elicited by increasing the internal tissue temperature compared with the adjacent tissue [34]. Gray et al. [12] conducted a study to compare the effects of short-wave diathermy, LIUS and LLLT in patients with TMJ dysfunction. They found no notable difference in the results of all treatment modalities. Nevertheless, these modalities induced significant improvements compared with its placebo treatment.

The present study ran concurrently with a one conducted by Rai et al. [35]; they reported that therapeutic ultrasound is effective in the treatment of maxillofacial disorders through lessening pain and enhancing the healing property of soft tissues.

In adversary, Grieder et al. [36] conducted a study regarding the assessment values of ultrasound in the treatment of TMJ dysfunction and concluded that ultrasound was not effective alone in the treatment of such problems.

Oral exercise therapy including passive and active movements, stretching and strengthening exercises have proven to beneficially decrease the signs and symptoms related to TMJ dysfunction since they improve the mouth opening and mandibular movements $[37,38]$. In our trial, the patients were urged to use such types of exercises which reflected an improvement of the total scores of VAS, UW-QOL, and VCS at the end point of the treatment protocol.

The observed improvement in outcomes of patients treated by LIUS plus TET may be attributed to the ability of the ultrasound to: improve blood circulation to the target tissue, produce micro massage, remove waste products, accelerate the lymphatic drainage, improve the metabolic activities and increase the extensibility of soft tissue. Additionally, lessening of pain may be attributed to increased blood flow resulting in washing up of metabolites and the chemical mediators flow [39].

The study revealed that LIUS has a more superior effect when combined with the TET program in comparison to LLLT when combined with the same types of exercises in the treatment of trismus and its related pain among patients with HNC.

Given that there was no control group in this study, larger sample sizes are recommended for other prospective trials in order to overcome the limitations and challenges experienced during this study.

In conclusion, based on the results of this study, LIUS, LLLT, and TET emerge as valuable treatment methods of trismus and pain for patients following HNC. Despite a small sample size, this particular study proved that combined program of LIUS and TET had more superior effect when compared to LLLT and/or TET in the treatment of 
TMJ pain and trismus following HNC and can be considered as adjunct methods in the treatment of such problems.

\section{CONFLICT OF INTEREST}

No potential conflict of interest relevant to this article was reported.

\section{REFERENCES}

1. Jemal A, Bray F, Center MM, Ferlay J, Ward E, Forman D. Global cancer statistics. CA Cancer J Clin 2011;61:69-90.

2. Jemal A, Siegel R, Ward E, Murray T, Xu J, Thun MJ. Cancer statistics, 2007. CA Cancer J Clin 2007;57:4366.

3. Boyle P, Levin B. World cancer report 2008. Lyon: International Agency for Research on Cancer Publication; 2008.

4. Al-Belasy FA. Ultrasound-guided drainage of submasseteric space abscesses. J Oral Maxillofac Surg 2005;63:36-41.

5. Brooke RI. Facial trismus and myofascial pain associated with infections and malignant disease. Oral Surg Oral Med Oral Pathol 1988;66:450.

6. Gomez DR, Zhung JE, Gomez J, Chan K, Wu AJ, Wolden SL, et al. Intensity-modulated radiotherapy in postoperative treatment of oral cavity cancers. Int J Radiat Oncol Biol Phys 2009;73:1096-103.

7. Goldstein M, Maxymiw WG, Cummings BJ, Wood RE. The effects of antitumor irradiation on mandibular opening and mobility: a prospective study of 58 patients. Oral Surg Oral Med Oral Pathol Oral Radiol Endod 1999;88:365-73.

8. Wang CJ, Huang EY, Hsu HC, Chen HC, Fang FM, Hsiung CY. The degree and time-course assessment of radiation-induced trismus occurring after radiotherapy for nasopharyngeal cancer. Laryngoscope 2005;115:1458-60.

9. Ichimura $\mathrm{K}$, Tanaka $\mathrm{T}$. Trismus in patients with malignant tumours in the head and neck. J Laryngol Otol 1993;107:1017-20.

10. Chua DT, Lo C, Yuen J, Foo YC. A pilot study of pentoxifylline in the treatment of radiation-induced trismus. Am J Clin Oncol 2001;24:366-9.
11. Buchbinder D, Currivan RB, Kaplan AJ, Urken ML. Mobilization regimens for the prevention of jaw hypomobility in the radiated patient: a comparison of three techniques. J Oral Maxillofac Surg 1993;51:8637.

12. Gray RJ, Quayle AA, Hall CA, Schofield MA. Physiotherapy in the treatment of temporomandibular joint disorders: a comparative study of four treatment methods. Br Dent J 1994;176:257-61.

13. Leung MS, Cheing GL. Effects of deep and superficial heating in the management of frozen shoulder. J Rehabil Med 2008;40:145-50.

14. Shiraishi R, Masaki C, Toshinaga A, Okinaga T, Nishihara T, Yamanaka N, et al. The effects of low-intensity pulsed ultrasound exposure on gingival cells. J Periodontol 2011;82:1498-503.

15. Hashish I, Harvey W, Harris M. Anti-inflammatory effects of ultrasound therapy: evidence for a major placebo effect. Br J Rheumatol 1986;25:77-81.

16. McNeely ML, Armijo Olivo S, Magee DJ. A systematic review of the effectiveness of physical therapy interventions for temporomandibular disorders. Phys Ther 2006;86:710-25.

17. Nicolakis P, Erdogmus B, Kopf A, Ebenbichler G, Kollmitzer J, Piehslinger E, et al. Effectiveness of exercise therapy in patients with internal derangement of the temporomandibular joint. J Oral Rehabil 2001;28:1158-64.

18. Ferrante M, Petrini M, Trentini P, Perfetti G, Spoto G. Effect of low-level laser therapy after extraction of impacted lower third molars. Lasers Med Sci 2013;28:845-9.

19. Alan H, Yolcu U, Koparal M, Ozgur C, Ozturk SA, Malkoc S. Evaluation of the effects of the low-level laser therapy on swelling, pain, and trismus after removal of impacted lower third molar. Head Face Med 2016;12:25.

20. Wu VW, Lam YN. Radiation-induced temporo-mandibular joint disorder in post-radiotherapy nasopharyngeal carcinoma patients: assessment and treatment. J Med Radiat Sci 2016;63:124-32.

21. Agrawal J, Shenai PK, Chatra L, Kumar PY. Evaluation of normal range of mouth opening using three finger index: South India perspective study. Indian J Dent Res 2015;26:361-5.

22. Ringash J, Bezjak A. A structured review of quality of 
life instruments for head and neck cancer patients. Head Neck 2001;23:201-13.

23. Kanatas AN, Rogers SN. A national survey of healthrelated quality of life questionnaires in head and neck oncology. Ann R Coll Surg Engl 2004;86:6-10.

24. Rogers SN, Lowe D. Screening for dysfunction to promote multidisciplinary intervention by using the University of Washington Quality of Life Questionnaire. Arch Otolaryngol Head Neck Surg 2009;135:369-75.

25. The British Pain Society. Pain scales in multiple languages [Internet]. London: The British Pain Society; c2014 [cited 2018 Nov 15]. Available from: https:// www.britishpainsociety.org/british-pain-societypublications/pain-scales-in-multiple-languages/.

26. Dijkstra PU, Sterken MW, Pater R, Spijkervet FK, Roodenburg JL. Exercise therapy for trismus in head and neck cancer. Oral Oncol 2007;43:389-94.

27. Israel HA, Syrop SB. The important role of motion in the rehabilitation of patients with mandibular hypomobility: a review of the literature. Cranio 1997;15:7483.

28. Lee LY, Chen SC, Chen WC, Huang BS, Lin CY. Postradiation trismus and its impact on quality of life in patients with head and neck cancer. Oral Surg Oral Med Oral Pathol Oral Radiol 2015;119:187-95.

29. Pauli N, Johnson J, Finizia C, Andrell P. The incidence of trismus and long-term impact on health-related quality of life in patients with head and neck cancer. Acta Oncol 2013;52:1137-45.

30. Carrillo JS, Calatayud J, Manso FJ, Barberia E, Martinez JM, Donado M. A randomized double-blind clinical trial on the effectiveness of helium-neon laser in the prevention of pain, swelling and trismus after removal of impacted third molars. Int Dent J 1990;40:316.

31.Zecha JA, Raber-Durlacher JE, Nair RG, Epstein JB, Elad S, Hamblin MR, et al. Low-level laser therapy/ photobiomodulation in the management of side effects of chemoradiation therapy in head and neck cancer: part 2: proposed applications and treatment protocols. Support Care Cancer 2016;24:2793-805.

32. Roynesdal AK, Bjornland T, Barkvoll P, Haanaes HR. The effect of soft-laser application on postoperative pain and swelling: a double-blind, crossover study. Int J Oral Maxillofac Surg 1993;22:242-5.

33. Fernando S, Hill CM, Walker R. A randomised double blind comparative study of low level laser therapy following surgical extraction of lower third molar teeth. Br J Oral Maxillofac Surg 1993;31:170-2.

34. Esposito CJ, Veal SJ, Farman AG. Alleviation of myofascial pain with ultrasonic therapy. J Prosthet Dent 1984;51:106-8.

35. Rai S, Kaur M, Goel S, Panjwani S, Singh S. Prospective utility of therapeutic ultrasound in dentistry: review with recent comprehensive update. Adv Biomed Res 2012;1:47.

36. Grieder A, Vinton PW, Cinotti WR, Kangur TT. An evaluation of ultrasonic therapy for temporomandibular joint dysfunction. Oral Surg Oral Med Oral Pathol 1971;31:25-31.

37. Oh DW, Kim KS, Lee GW. The effect of physiotherapy on post-temporomandibular joint surgery patients. J Oral Rehabil 2002;29:441-6.

38. Tuncer AB, Ergun N, Tuncer AH, Karahan S. Effectiveness of manual therapy and home physical therapy in patients with temporomandibular disorders: a randomized controlled trial. J Bodyw Mov Ther 2013;17:302-8.

39. Calixtre LB, Moreira RF, Franchini GH, Alburquerque-Sendin F, Oliveira AB. Manual therapy for the management of pain and limited range of motion in subjects with signs and symptoms of temporomandibular disorder: a systematic review of randomised controlled trials. J Oral Rehabil 2015;42:847-61. 